\title{
Heat treatment furnace area cover crane girder factory owner durability analysis of a cold rolling plant
}

\author{
Hongbin Liu ${ }^{1 \mathrm{~b}}$ Yijiang $\mathrm{Li}^{2 \mathrm{a*}}$ \\ ${ }^{1}$ University of Science and Technology Liaoning , Anshan, Liaoning, 114051, China

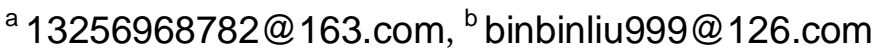

Keywords: crane beam; stress test; Fatigue test; durability

Abstract. A old rolling factory owners plant cover type heat treatment furnace area crane beam, is riveting real abdominal crane beam, has been working more than forty years, and repeatedly subjected to dynamic loading crane, will produce fatigue failure of steel, especially at the rivet connection work Experience close durable life, prone to fatigue damage. Affect the safety of the production plant. Hence the need for durability workshop crane beam to make a comprehensive evaluation, which does not affect the scientific and rational determination of reinforcement under normal production conditions, thereby reducing project investment.

\section{Project Overview}

A cold rolling factory was built in the 1950's, the multi-span was not same high single bent structure, cover type heat treatment furnace area is located across B $\sim \Gamma, \mathrm{B}$ column spacing of $6 \mathrm{~m}, \Gamma$ column spacing 12 meters, the plant column for the lattice, crane beam-shaped caulking member for the rail top elevation of 14 meters. Heat treatment furnace area covers a total of seven cranes, crane run due to frequent and extended service structure connecting rivet $\Gamma$ column crane beam with a more severe damage and loss, Figure 1shows $\Gamma$ out of them (37) - (39) No shedding rivets crane beam axis, in order to ensure normal production safety, now on $\Gamma$ column crane girder comprehensive research and testing in order to provide reinforcement scheme crane beam.

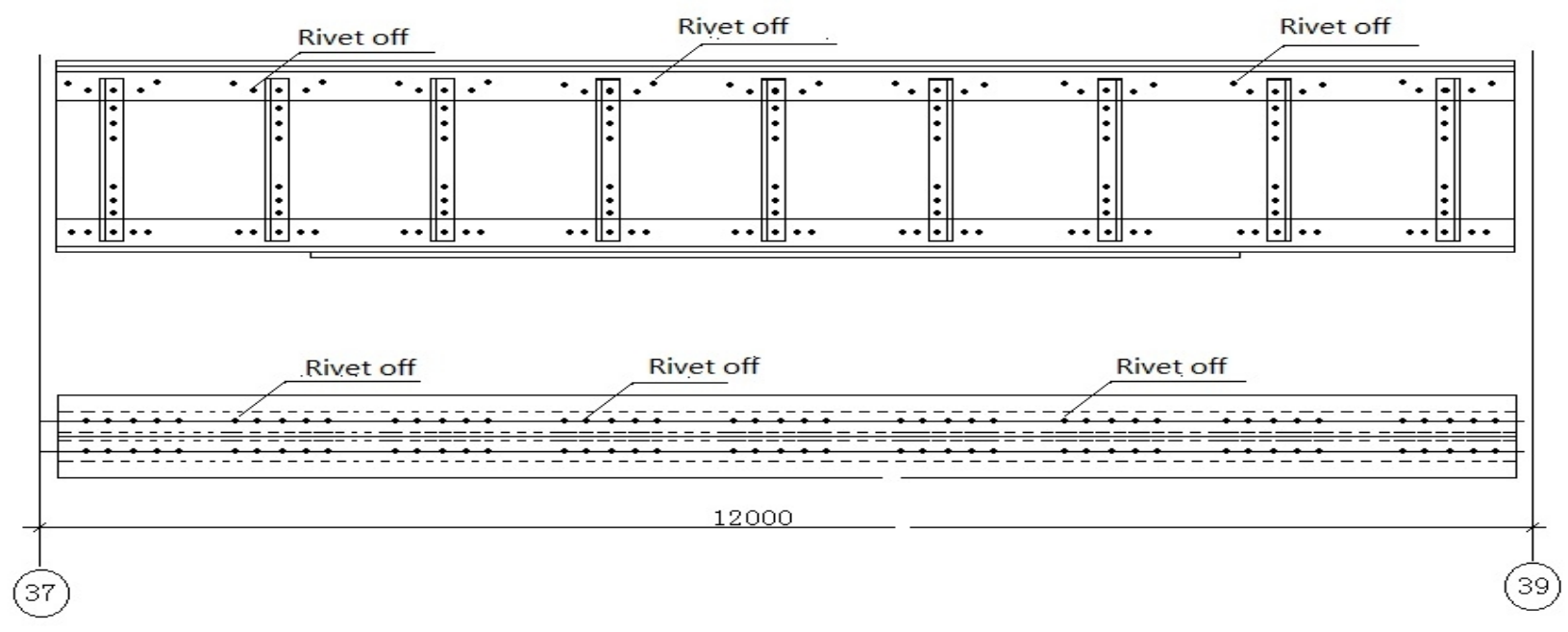

Figure 1.г column crane girder rivet shedding

\section{Bearing Capacity and Analysis}

According importance factor analysis of material strength steel structure of the crane beam steel for the Q345, Q235 steel rivets is, in consideration of the actual structure of the influence of various factors on the bearing capacity of the structural calculation, structural calculations in Table 1, which, $\mathrm{r}_{0}$ is The importance factor of 1 . 
Table 1. column crane beam checking results

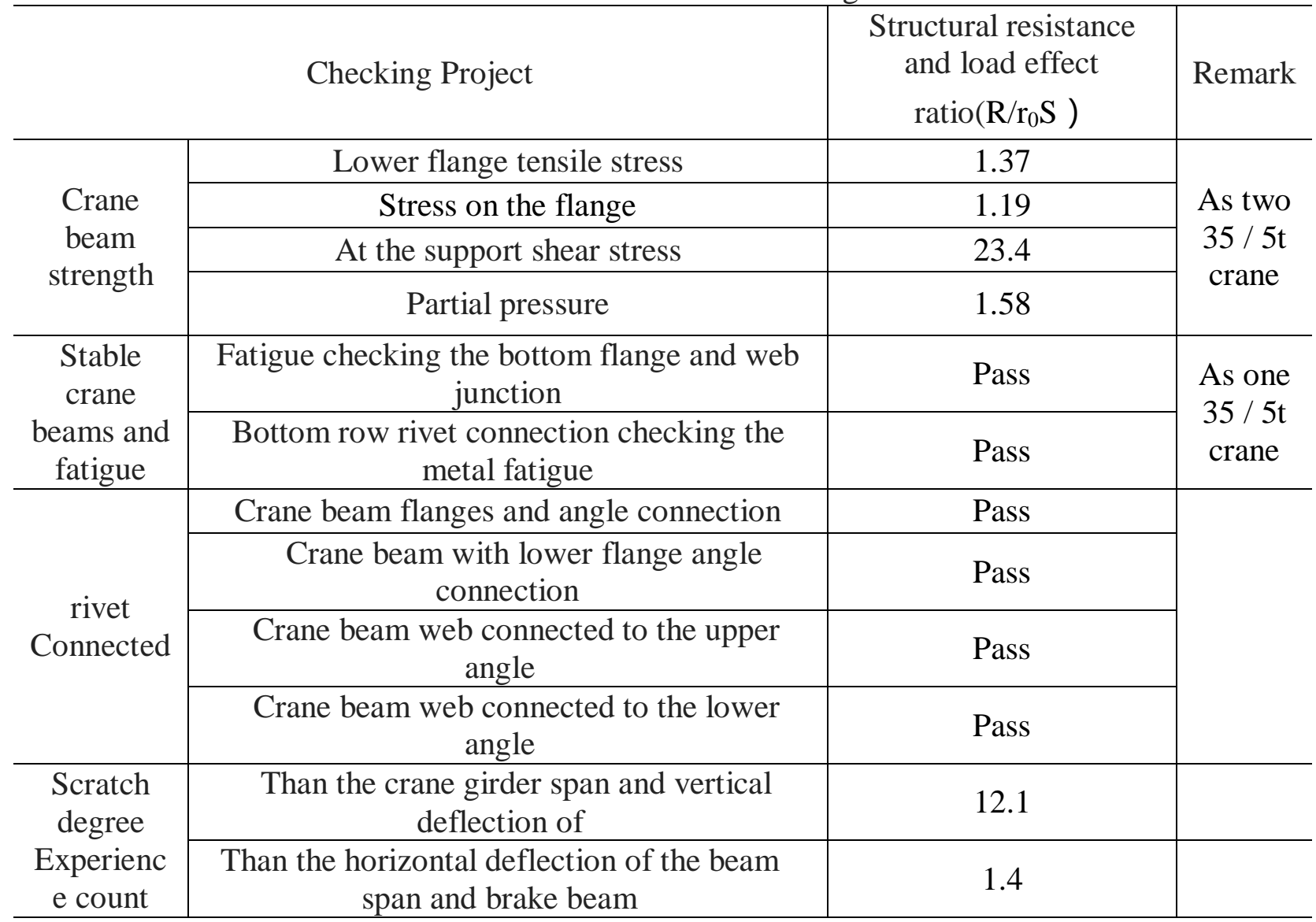

\section{Crane beam test}

According to the situation and crane usage, to ensure the durability of the crane beam, the need for the crane girder stress testing and fatigue testing.

Stress Test Results. For $\Gamma$ column (4) to (49) line of crane beam angle with the crane beam flange and web connections riveting at the more severe loosening, shedding phenomenon. Now extract $\Gamma$ column (37) - (39) line crane girder stress testing and fatigue testing. The content of test for crane beam at various points across the most disadvantaged section of the tensile and compressive stress test; the magnitude of change under the stress test each crane girder running and brakes working conditions. Location crane girder crane span maximum bending moment is shown in Figure2, the test strain gauges in the most unfavorable section of the crane beam, the specific arrangement of the measuring point position shown in Figure 3. The test results are shown in Table 2

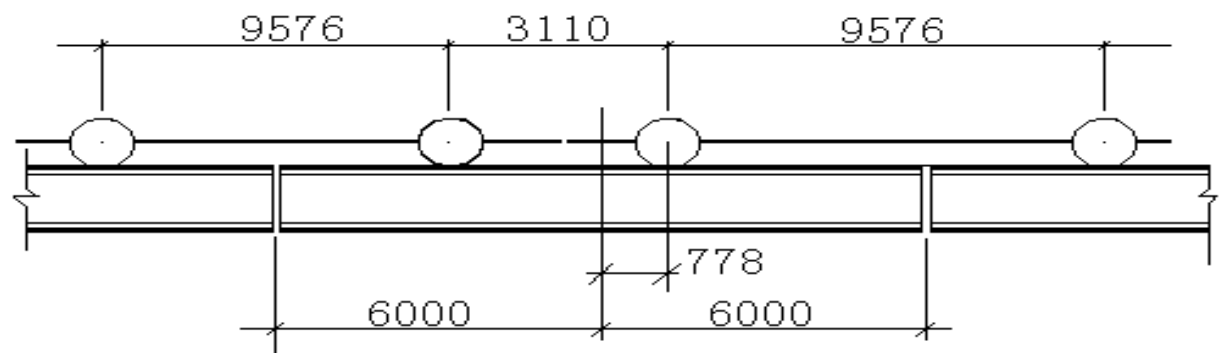

Figure 2. Location Map crane span when the greatest moment 

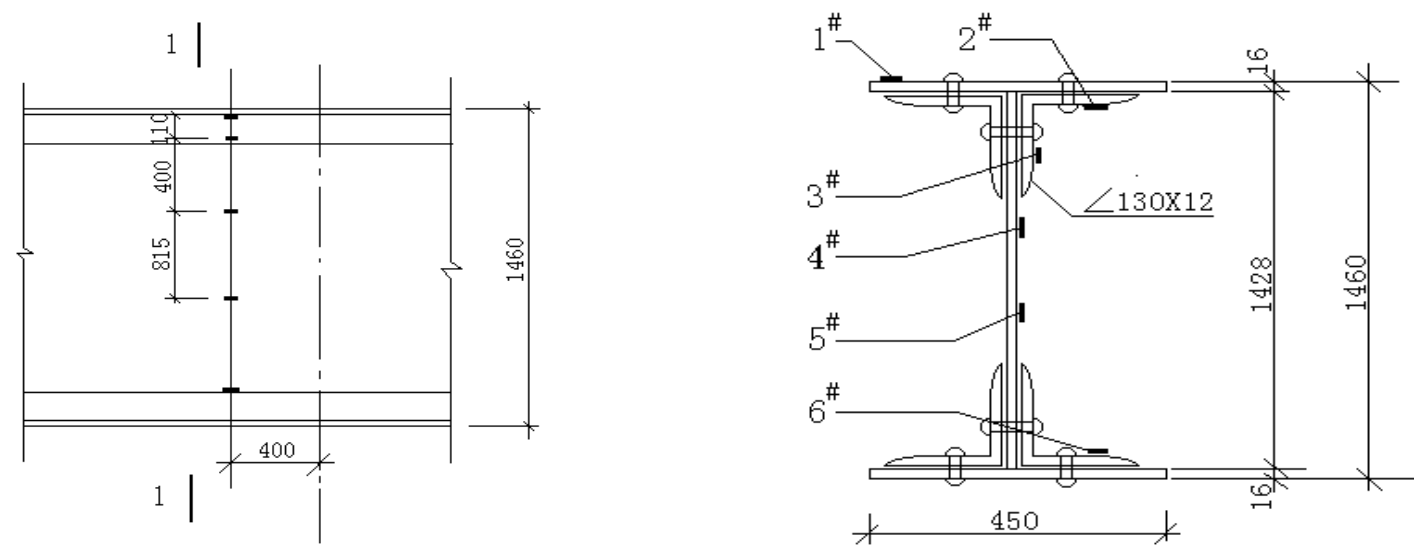

Figure 3. Strain measuring points and number

Table 2. Stress Test Result

\begin{tabular}{l|c|c|c|c|c|c}
\hline \multirow{2}{*}{ Working conditions } & \multicolumn{7}{|c}{ Stress test point (MPa) } \\
\cline { 2 - 7 } & $1 \#$ & $2 \#$ & $3 \#$ & $4 \#$ & $5 \#$ & $6 \#$ \\
\hline $\begin{array}{l}\text { Two cranes full stop at the moment } \\
\text { the most unfavorable position }\end{array}$ & -37.8 & -38.92 & -31.72 & -3.36 & 50.4 & 70.16 \\
\hline $\begin{array}{c}\text { Two cranes full stop at the moment } \\
\text { Most unfavorable position (trolley } \\
\text { line from east to west) }\end{array}$ & -35.1 & -38.9 & -32.68 & -4.81 & 48.0 & 70.16 \\
$\begin{array}{c}\text { Two cranes loaded (car near the test } \\
\text { beam) running from south to north }\end{array}$ & -53.8 & -45.65 & -42.29 & -25.9 & 49.5 & 74.97 \\
\hline $\begin{array}{c}\text { Two cranes loaded (car near the test } \\
\text { beam) by }\end{array}$ & -52.8 & -39.89 & -35.08 & -22.1 & 43.2 & 65.84 \\
\hline
\end{tabular}

stress fatigue test results. To bear the load of the crane girder crane belonging amplitude loading, this trial based on linear cumulative damage rule Palmyra-Miner and the amplitude fatigue converted into constant amplitude fatigue calculation.

37-39 rows of $\Gamma$ column crane beams under normal production status 24 hours of continuous tracking of dynamic stress testing. Dynamic strain measurement, tape recording. This test is only counted 3, \# 5 and \# 6-point result, using rain flow analysis results are shown in Table 3

Table 3. Fatigue Test Results

\begin{tabular}{c|c|c|c}
\hline $\begin{array}{c}\text { Measuring } \\
\text { point }\end{array}$ & $\begin{array}{c}\text { Day number of stress } \\
\text { cycles } \Sigma n_{i}^{*}\end{array}$ & $\begin{array}{c}\text { Under run effect } \\
\text { coefficient } \\
\alpha_{1}=\Delta \sigma_{\mathrm{e}}{ }^{*} / \Delta \sigma_{1}\end{array}$ & $\begin{array}{c}\text { Projections have been } \\
\text { used for 45 years the } \\
\text { number of cycle } \\
\text { (Million times) }\end{array}$ \\
\hline $3 \#$ & 533 & 0.25 & 875 \\
\hline $5 \#$ & 531 & 0.4 & 584 \\
\hline $6 \#$ & 356 & 0.8 & 872 \\
\hline
\end{tabular}

Table:

$$
\Delta \sigma_{e}^{*}=\left(\frac{\sum n_{i} \cdot\left(\Delta \sigma_{i}^{*}\right)^{\beta}}{\sum n_{i}}\right)^{1 / \beta}
$$

among them: $\Delta \sigma_{a}^{*}$-The number of cycles corresponding to the damage equivalent stress amplitude 
$\Delta \sigma_{i}^{*}$ - Test the i-th stress amplitude.

$\Sigma n_{i}$ - Structure number of stress cycles represented by the expected service

1 -coefficient. In this connection according to the third class, a value of 3 .

For each possible site of fatigue failure, fatigue performance evaluation the following formula:

$$
\frac{n_{1}}{N_{1}}=k
$$

$\mathrm{n}_{1}$ - number of stress cycles for the site has been used, see Table 3.3

$\mathrm{N}_{1^{--}}$for parts of the equivalent stress amplitude Dse 1 corresponding fatigue life, according to the relevant provisions of the "Steel Design Code" (GBJ 50017-2003) Calculation

$\mathrm{k}-$ - assessment coefficient, $\mathrm{k}$ is greater than or equal to 1 , indicating that

fatigue damage is likely to occur, does not appear to fatigue failure, $\mathrm{k}$ value must be less than one.

Fatigue evaluation results are shown in Table 4

Table 4. Fatigue Assessment Results

\begin{tabular}{c|c|c|c|c|c}
\hline $\begin{array}{c}\text { Crane } \\
\text { Beam }\end{array}$ & $\begin{array}{c}\text { Calculate the most } \\
\text { unfavorable position of } \\
\text { the maximum stress } \\
\text { amplitude according to } \\
\text { static stress test } \\
\text { results(Mpa) }\end{array}$ & $\begin{array}{c}\text { Equivalent } \\
\text { stress } \\
\text { amplitude } \\
\text { Dsel (Mpa) }\end{array}$ & $\begin{array}{c}\text { Projections } \\
\text { have been used } \\
\text { for 45 years } \\
\text { the number of } \\
\text { cycles(Million } \\
\text { times) }\end{array}$ & $\begin{array}{c}\text { Fatigue life } \\
\mathrm{N}_{1} \text { (Million } \\
\text { times) }\end{array}$ & $\begin{array}{c}\text { Assess } \\
\text { ment } \\
\text { coeffici } \\
\text { ent } \mathbf{k}\end{array}$ \\
\hline $\begin{array}{c}\text { Top } \\
\text { flange } \\
(3 \#)\end{array}$ & -51 & 21.42 & 875 & 33100 & 0.026 \\
\hline $\begin{array}{c}\text { Webs } \\
(5 \#)\end{array}$ & 59.4 & 40.4 & 872 & 4943 & 0.18 \\
\hline $\begin{array}{c}\text { Lower } \\
\text { flange } \\
(6 \#)\end{array}$ & 90 & 72.0 & 584 & 873 & 0.67 \\
\hline
\end{tabular}

Value can be seen from the table, $\mathrm{k}$ values of all parts of less than 1, indicating that these parts of the fatigue strength can still meet the requirements, which the lower flange $\mathrm{k}$ highest value reached 0.67 , the fatigue strength of the weakest link.

\section{Conclusion and reinforcement measures}

By this cold rolling factory owners plant internal force, section strength and durability of materials structure analysis section heat treatment furnace area cover crane beam, the crane beam we get a complete and reliable data, to avoid blind reinforcement, waste engineering investment, specific reinforcement program are as follows:

r columns (5) to (49) riveted solid web girder crane off rivet processing. Using high strength bolts (friction type) to replace the damaged rivet, use smaller diameter than the original hole bolt 1 to $3 \mathrm{~mm}$, requiring dirt, paint, rust steel surface near the skin pores, etc. must be removed. Selected high-strength bolts M22,10.9 level. 
$\Gamma$ column crane beams and brake beam reinforcement between the vertical support. Original $\Gamma$ column crane beam between vertical support beams and brake setting position does not comply with current regulatory requirements, the proposed replacement setting. Specifically Figure 4.

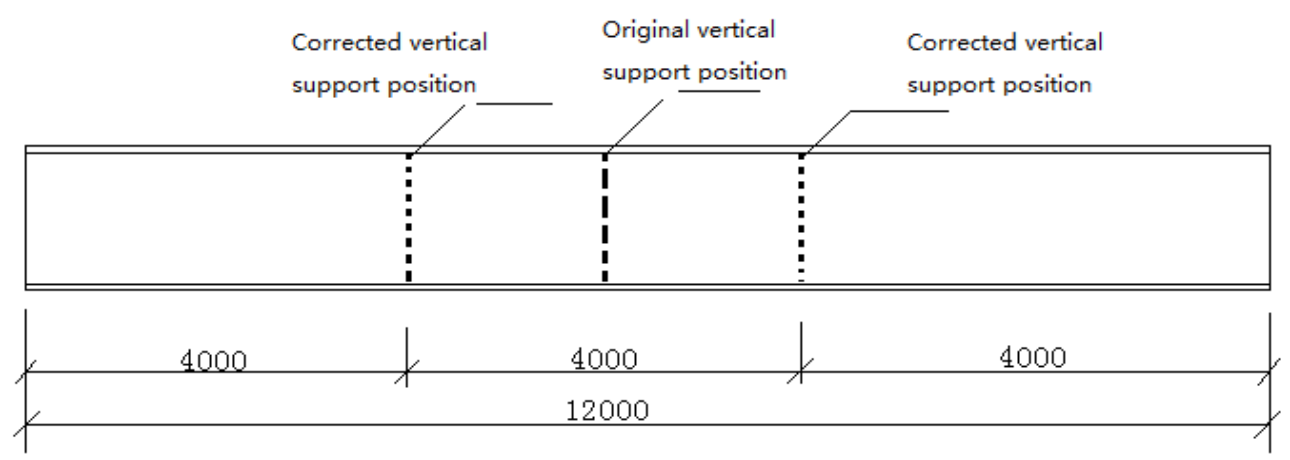

Figure 4. Layout vertical support

Vertical support structure and the cross-sectional dimensions correct position after the original vertical support whichever spot welding process.

\section{Reference}

[1] GB 50144-2008: Standard for appraisal reliability of industrial building and structure (China Architecture and Building Press, Beijing, 2008). (in Chinese)

[2] GB/T50344-2004: Technical standards for inspection of building structure (China Architecture and Building Press, Beijing, 2004). (in Chinese)

[3] GB5009-2012 : Load code for the design of building structure (China Architecture and Building Press, Beijing, 2012). (in Chinese)

[4] GB50017-2015: Code for design of Steel structure (China Architecture and Building Press, Beijing, 2015). (in Chinese)

[5] Haosong Chang, Xinliang Jiang, Xiaorui Li.. Fatigue Performance Testing and Analysis of Cranegirders for A Steel Making Plant (Industrial Construction, Vol.42 2014). (in Chinese) 